\title{
WRITING GAMES
}

\section{CONTINUITYAND CHANGE IN THE DESIGN AND DEVELOPMENT OF QUIZ SHOWS IN ITALY}

\author{
Alex Fiacco and Massimo Scaglioni \\ Dipartimento di Scienze della Comunicazione e dello Spettacolo \\ Università Cattolica del Sacro Cuore \\ Via S. Agnese 2 \\ 20123 Milan - Italy \\ Massimo.scaglioni@unicatt.it \\ axel.fiacco@gmail.com
}

\begin{abstract}
As in the United States and in many countries across Europe, the quiz show was a founding genre for Italian television as far back as the 1950s: because of their broad appeal, such game shows as Lascia o raddoppia and II musichiere contributed strongly to television's burgeoning popularity during the subsequent decades. Since then, the quiz show has traversed different eras of television history, with partial and gradual changes to its textual features, aesthetics and narratives, as well as its production routines. Since the 1980s, with deregulation and the advent of commercial television, the Italian game-show market has become more international and more reliant on formats. In the genre's long history, the 'hidden profession' of writing TV games exhibits elements of both continuity and change. The needs of format-adaptation have highlighted two main areas of "localization": question-writing and casting. This essay explores the profession of game-show writer in Italy and how the role has evolved. It adopts a historical framework to illuminate the continuity and change in the profession, in relation to a broader history of both the genre and the television medium, while also seeking to outline both the specificity of the Italian TV context and its connections with an international environment.
\end{abstract}

Keywords: Quiz And Game Show, Italian Television, Game-Show Writer, Tv Autorship, Casting.

\section{A Founding Genre and Its Historical Evolution as a National and Supranational Phenomenon}

The game show is a founding genre for the television medium: its pre-media roots lie in the tradition of 'parlour games, ${ }^{1}$ its media roots, in the history of 1930 s American radio broadcasting. ${ }^{2}$ From the 1940 s and 50 s onwards, prize competitions were a prominent feature of many countries' television schedules - in the United States and in Europe swinging between huge popularity and partial marginalization: ${ }^{3}$ in any case, games have been ever present throughout television broadcasting history.

\footnotetext{
1 See Raymond Williams, Television: Technology and Cultural Form, Routledge, 2003 (original edition, 1974)

2 For the history of the genre, see in particular William Boddy, 'The Quiz Show', in Glen Creeber (ed.), The Television Genre Book, BFI, 2001, p. 162-164; Su Holmes, The Quiz Show, Edinburgh University Press, Edinburgh, 2008

3 The best-known example is the genre's fall from favour in the USA after the Van Doren scandal, in the late 50s, which signalled the end of the halcyon days for the big-money quiz show.
} 
Television game shows' importance and success have various explanations. The genre is notable for its particular flexibility and adaptability: a recurring formula ('one or more players, a dilemma to resolve, and a prize or final jackpot' is the pithiest definition) ${ }^{4}$ with a variety of specific subgenres (the 'classic quiz' show, based on questions posed directly to the contestant; the 'light quiz,' where the dilemma is embodied not in a question but rather in one or more skills; the 'game of chance,' where the dilemma is solved by fortune only; etc. $)^{5}$ and different target audiences, formats and scheduling slots (network versus syndication; primetime versus daytime versus late night).

Although the genre is ever present, it has still not received the critical attention that it undoubtedly merits. As John Fiske has emphasized, the quiz is a source of both popular entertainment and intellectual disdain. ${ }^{6}$ Or as William Boddy sums up, "[a]s nearly authorless texts, the quiz show has frustrated traditional authorist and generic methods of analysis imported from literature and film studies. ${ }^{7}$

Dedicating a research study to the 'hidden professions' of the game show and, in particular, to quiz writing, seems paradoxical only in light of the negative prejudices that the genre arouses. This essay aims to tackle this contradiction head-on and to show how game-show production has always involved a complex creative effort. The nature of this effort has changed progressively in some respects, while remaining the same in others, through the transitions from one era in television history to another. As production studies have stressed, TV authorship is multiple, collaborative and highly negotiated. ${ }^{8}$ In the history of Italian television, a person performing creative work for TV has always been generally referred to as an 'autore,' literally 'author' (plural: autori). This fairly ambiguous term, which is still in common use, is rooted in the humanist-literary tradition that has strongly characterized the origins of Italian broadcasting since the 1950s and alludes to a whole host of roles, from devising to producing. As we shall see, a major change in quiz production has been that the profession of game show writer has become more and more specialized and fragmented, leaving behind the ideal model of a single 'author.'

Alongside the variable of time, the spatial dimension must be borne in mind, too, of course, since the genre's history varies, sometimes significantly, from country to country. The history of the game show is, therefore, strongly national but also decidedly transnational. For, since TV's origins, the models (and the professional skillsets) have transcended national boundaries, well before an international formats market developed - precisely for the exchange of gameshow programmes - from the 80 s and $90 \mathrm{~s}$. Indeed, while games are extremely universal, they also require specific tailoring to traditions, cultures and - not least - the particular needs of the national television markets.

This essay aims to trace how the profession of writing game shows developed in the Italian domestic television context. After outlining the principal strands of continuity and change in the roles and practices of the game-show writers, from the beginnings to more recent times, we shall focus closely on the two main aspects of devising and writing contemporary television quizzes: question-writing and casting. The essay adopts not only a historical perspective but also a production studies framework to illuminate the routines, reflexive perceptions, and professional assumptions that characterize the main fields of game-show creativity. ${ }^{9}$ Following an 'integrated cultural-industrial method of analysis, ${ }^{10}$ we have chosen to integrate a more traditional approach based on institutional and textual/genre

\footnotetext{
${ }^{4}$ Axel Fiacco, Fare Televisione. I format, Laterza, 2013, p. 11.

5 These are some of the categories noted in Axel Fiacco, Fare televisione, op. cit.

6 See John Fiske, 'Quizzical Pleasures', in Television Culture, New York and London, Routledge, 1987.

7 William Boddy, 'The Quiz Show', op. cit. On this point, see also Jerome Bourdon, 'Old and New Ghosts. Public Service Television and the Popular. A History', European Journal of Cultural Studies 7 (3), 2004, p. 283-304; and Peppino Ortoleva, 'Scatola dei giochi, maestra di gioco. La componente ludica dello spettacolo televisivo', in Aldo Grasso, Storie e culture della televisione italiana, Mondadori, 2013.

8 For a general picture of creative work in contemporary cultural industries, see, in particular, David Hesmondhalgh, The cultural industries, Sage, London, 2007.

9 See John Thornton Caldwell, Production Culture. Industrial Reflexivity and Critical Practice in Film and Television, Duke University Press, Durham and London, 2008; Vicky Mayer, Miranda J. Banks, John Thornton Caldwell, Production Studies. Cultural studies of Media Industries, Routledge, 2009.

10 J.T. Caldwell, Production Culture, p. 4.
} 
history with field work grounded in interviews with quiz writers and TV managers. ${ }^{11}$

According to the periodization model advanced by John Ellis, television history in Italy, as in other European countries, can be broken down into three broad ages..$^{12}$ First, the age of scarcity coincides with the public-service monopoly, when the RAI - Radiotelevisione Italiana - was the only organization authorized for nationwide television broadcasting, through its two channels (1954-79). Second, the age of availability corresponds, in Italy, to the advent and triumph of the commercial networks founded by the magnate Silvio Berlusconi, which evolved into a group that was a mirror image of the public body, with three national networks for the RAI and three for the Berlusconi-owned Fininvest, later Mediaset, (1980-2003). ${ }^{13}$ And third, the age of plenty equates to the decade marked by a partial opening-up of the market (as the RAI and Mediaset were joined by a third major player, namely pay-TV outfit Sky Italia from the multinational NewsCorp group), the process of digitalization, the growth of the multichannel offering to around two hundred networks, and a progressive fragmentation of consumption (2003-13). ${ }^{14}$

The history of the game show interwove with all these eras in Italian television, as the shows gradually evolved different functions, thus maintaining strands of continuity with the genre's past while also creating new departures. Game show history can be analysed on three fronts. First, the TV quiz acquired a different value in the context of the television medium's overall offering, also depending on its consumption and popularity, and hence on the cultural dimension, in the broadest sense. Second, it established a relationship that differs from the international models of TV games, especially American ones, in various ways, including production practices and the payment of rights. And third, its 'authoriality,' along with the various professional groups involved in the process of writing the programmes, manifests in an equally distinctive way.

As for the role that game shows have played in Italy's television output, the three ages of television mark quite significant and radical changes in the genre's history. In the age of the public monopoly, the game show was a prime embodiment of the RAl's mission to 'entertain while educating' or 'educate while entertaining.' Alongside information programmes, purely educational programmes and outright entertainment programmes, the TV quiz was a fundamentally important genre for the RAI in its early days. In particular, its immediate popularity helped to spread the television-viewing habit far and wide and, therefore, to encourage the progressive take-up of TV licences.

A show like Lascia o raddoppia (1955-59), presented by a young Italian-American broadcaster from the world of radio, Mike Bongiorno, ${ }^{15}$ was initially scheduled for Saturday evenings but was moved to Thursdays after protests from cinema owners, whose theatres were left empty by the stunning success of the TV quiz. Lascia o raddoppia, like II musichiere (1957-60), Campanile sera (1959-62), Telematch (1957-58) and, later, Rischiatutto (1970-74) are the most popular exemplars of the 'Italian way' for quiz shows. All flagship primetime RAl programmes, they were based on hybridizing the skeleton of an American-inspired game show format with Italian-style entertainment elements. The aim was to focus on the originality of the contestants, who rapidly became popular heroes, on the personality cult of the presenters (like Mike Bongiorno and Mario Riva), and on the various entertaining 'side dishes' (such as the presenter's ever-present glamorous assistant). In this period, the Italian-style game show was a recreational rite that drew viewers in their millions (sometimes over twenty million) and was celebrated in the next day's papers, with the

\footnotetext{
11 The essay relies on a series of six interviews held between May and July 2013 with game-show writers and Italian television managers. We chose to interview two popular Italian quiz writers whose long careers cover different stages in TV history, two younger writers whose careers have developed during the most recent stage of game show development, and two TV managers heavily involved in entertainment and game show production since the 1980s. Our warmest thanks go, in particular, to Ludovico Peregrini, Davide Tortorella, Ilenia Ferrari, Angelo Mandelli, Lillo Tombolini and Carlo Freccero.

12 John Ellis, Seeing Things: Television in an Age Of Uncertainty, I.B. Tauris, 2000

13 On the process of the commercialization of TV in Italy and on Silvio Berlusconi's TV, see in particular Luca Barra, Massimo Scaglioni, 'Berlusconi's television, before and after. The 1980s, innovation and conservation', Comunicazioni Sociali 1 (2013), p. $79-89$.

14 See Massimo Scaglioni, La tv dopo la tv. II decennio che ha cambiato la televisione: scenario, offerta, pubblico, Vita e Pensiero, 2011.

15 Mike Bongiorno was probably the most popular face on Italian television for over fifty years, surviving unscathed the transition from the original public-service television to the commercial world of the 80 s and 90 s. His last project, unrealized because of his death in 2009 , would have been a nostalgic reworking of the legendary Rischiatutto for pay television on Sky, entitled RiSKYtutto. On Mike Bongiorno, see Chiara Ferrari, 'National Mike. Global Host and Global Formats in Early Italian Television', in Tasha Oren, Sharon Shahaf, Global Television Formats. Understanding Television Across Borders, Routledge, 2012.
} 
low-down on the most popular contestants' exploits. It was the 'holy communion of the quiz.."16

With the dawn of commercial television and the networks controlled by Silvio Berlusconi, the game show's role gradually changed. Some remained primetime programmes, like Superflash (1982-84), Pentathlon (1985-87) and Telemike (1987-92), all featuring Mike Bongiorno, who had moved to the commercial networks from the RAI, in the classic Thursday-evening slot. Yet game shows also popped up at other times of day, becoming a winning formula for filling the schedule with home-produced programmes and attracting audiences at new times (through strip programming during the day, especially at lunchtime, with Bis and II pranzo è servito). In short, once a genuine event and an entertainment ritual, the game show became a daily, everyday and ordinary product.

The scheduling times that the TV quiz 'discovered' in the 90s (e.g. with La ruota della fortuna) include what would become the game show slot par excellence in contemporary television, namely the early-evening slot before the 8pm main evening news. This applies to both the leading public network - primarily with L'Eredità (2002-present) - and its private counterpart, Canale 5, with Passaparola (1999-2006), Chi vuol essere miliardario/milionario? (2000-11) and The money drop (2011-present). In this third age, the now-everyday quiz bedded down at a specific time of day: the return home from work. The game show thus acted as a lead-in to the main general national networks' evening news and primetime programming.

Across these three TV ages, the balance between home-grown game show output and the use of international models is just as different. In the early days, game shows were a handcrafted product liberally inspired by various exemplars from abroad (America, in particular). Sergio Pugliese, the RAI manager considered one of public TV's founding fathers, went several times to the USA, where he sent 'autori and future key figures of Italian television to learn from the productions overseas, where game shows immediately stood out. ${ }^{17}$ In this initial stage, the relationship with the templates was not always clear, especially when it came to buying the rights. The most famous case was Lascia $o$ raddoppia?, which although directly based on The $\$ 64000$ question, was claimed to be derived from the radio quiz Quitte ou double?, broadcast from the early 1950s on Radio Luxembourg, from which the RAl bought the rights. ${ }^{18}$ But, as with Musichiere, which was inspired directly and explicitly by the US show Name that tune, the 'Italianization' effort was considerable. For the program was 'completely reworked through the verve of [its autori] Garinei and Giovannini, who based it around the original presenting style of Mario Riva, ${ }^{, 19}$ introducing several variety elements into the game.

\footnotetext{
16 Interview with Ludovico Peregrini, a pioneering autore of TV game shows.

17 Paola Valentini, Televisione e gioco. Quiz e società italiana, Archetipolibri, 2013, p. 125

18 'It is hard to mark the legal trajectory of Lascia o Raddoppia? (...) As Albert Moran discusses, prior to Copyright Act of 1976 - which established more clear regulations about TV content reformatting - it was difficult to hold single national media industries accountable for importing and adapting formats and formulas without paying the proper licensing fees to the original producers'. Chiara Ferrari, 'National Mike', op. cit., p. 131.

19 Paola Valentini, Televisione e gioco, op. cit., p. 59.
} 


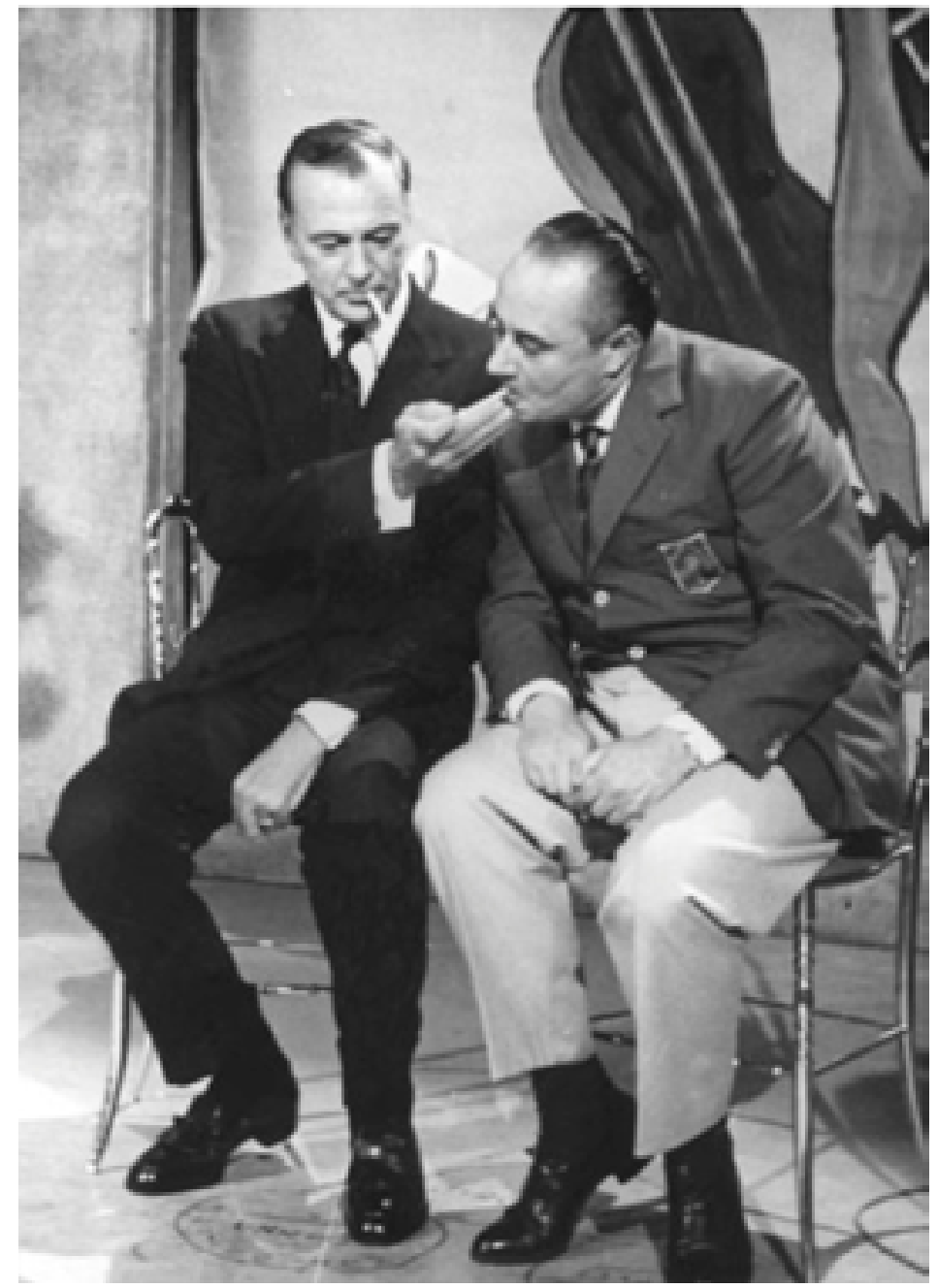

II musichiere host Mario smokes a sigarettes with Gary Cooper.

In the early days, the creative input comprised a general reworking of the American models. The borderline between 'free rewriting' and 'ripping off' is always a grey area, especially as there is still no legislative framework to regulate the international exchange of ideas and content. Yet when commercial TV arrived, the relationship with the foreign templates became clearer: as game shows spread across the schedules, and as demand for new shows grew, the most common approach was to buy the format - as with Ok, il prezzo è giusto! (1983-2001), an adaptation of The price is right thirty years on, or La ruota della fortuna (1989-2009), Italy's version of Wheel of fortune - even though plenty of new prototypes were devised, too. A singular case was M'ama non m'ama (1983-85), a game show for the Retequattro network (owned by the Mondadori publishing group, later acquired by Berlusconi's Fininvest during the same period). For this, Steve Carlin, legendary executive producer of The $\$ 64000$ question, was called in to create a game show all about love: "They said to him: "Invent a game show for Italy," and he, of course, with typical American originality, thought: "Italy=love." ${ }^{20}$ The most typical creative approach evolved from reinventing and recrafting shows that were based on foreign templates (adding huge doses of variety-inspired Italian popular culture) to adapting programmes after buying the rights on the international formats market, which meanwhile had begun to provide facilities for trading in television content. ${ }^{21}$ 
In the age of availability, the game show formats mainly comprised the mechanism of the game, i.e. the rules determining how a contestant wins the prize or jackpot; over the years, however, the market demanded an ever more detailed specification of all the formal aspects and the staging. The 2000s were notable not only for a more precise definition of the programming slots dedicated to game shows (in Italy, the early evening and the so-called 'access primetime,' between the evening news and the start of primetime proper) but also for the international success of formats that set out the programme's every aspect in minute detail - from the lights to the direction, and the presentation style to the musical jingles. In Italy, too, successful localized versions were staged of the English formats Who wants to be a millionaire? and The million pound drop. Most of the adaptation work concerned the format (the typical 'early-evening' game show slot demands a total duration of just over an hour), while every significant change had to be agreed with the format rights holders.

\section{The Quiz Professionals: The Writer from Deus Ex Machina to Specialist}

From the perspectives of the role that game shows played in the domestic television and cultural milieu and the relationship with the international templates, the three television ages are quite markedly different. Yet, from the perspective of the professional groups involved and the production routines deployed, we can detect significant strands of continuity, especially between the television of the early days, during the RAI monopoly, and the commercial TV of the 1980s and 90s, although there is less common ground with contemporary TV after the 2000s.

Indeed, the transition from the first age to the second seems not to have radically changed how the shows were devised and written. The professional groups involved were largely the same, as were the working methods. Although the educational aspirations of the early television died the death, and although advertising and the new techniques of competitive scheduling acquired a central role, the new commercial television attracted presenters and working teams who were already active in the public television. Indeed, Italian 'quiz king' Mike Bongiorno - who had popularized the game show and, with it, television itself, in the 1950s - joined Berlusconi's TV empire and became directly involved in the planning and organizing effort at the new network operator, recreating (physically and otherwise) the RAI environment from which he had arrived.

It all had to be set up from scratch: Mike [Bongiorno] had meetings with Berlusconi, who had a very hands-on role then in the project; together, they designed everything, even the changing-room area, [...] and decided how to divide up the studios. ${ }^{22}$

In the 80 s, as in the 50s, a game show had very few writers working on it (two or three at most). In close contact with the presenter, they oversaw all stages of writing and producing the programme. The autore, then, after helping to devise the programme's components, had to write the questions, supervise the casting to find the contestants, and take an active involvement in all the strategic meetings with the network producers and officials.

Television autori, and game show writers in particular, needed no specific background. They were often cultivated people with a humanistic education. Ludovico Peregrini, 'historic' autore for Italy's foremost game show presenter, Mike Bongiorno, began his career on the musical programme Settevoci (1966-70) after graduating in literature from Università Cattolica in Milan. After this experience, he became co-autore of Rischiatutto (1970-74), the second most popular of Bongiorno's quizzes, after Lascia o raddoppia?, with over twenty million viewers during its five series. In this era, the autore was above all a trusted associate of the presenter: from 1970, Peregrini collaborated on nearly all Bongiorno's programmes, following him from the RAI to commercial television. He became widely known as 'Signor No,' i.e. the on-camera adjudicator ruling on the correctness of the answers during many broadcasts. 
For Rischiatutto, Peregrini wrote all 36 questions on his own for every episode, which were simply reviewed by a RAI official for final approval. As an event followed by millions of viewers and reported in the next day's press, the Thursday evening quiz put the writer under real pressure:

On Friday, the day after Rischiatutto aired, La Notte, a Milan-based daily always ran a page with all our questions. So you saw your question in print, there to be read by professors, students, all and sundry; it was a big responsibility, and it certainly lent your work added spice. ${ }^{23}$

Besides scripting the line-up and the questions, the writer was also responsible for supervising the selection and recruitment of the contestants. This pattern of performing all the tasks in the creative process, aided by a small handful of assistants, is confirmed by another game show writer from way back when: Davide Tortorella, another of Mike Bongiorno's long-time collaborators. Like Peregrini, Tortorella also wrote all the quiz questions himself, together with a very tight group of two or three colleagues, and he also directly handled all the casting. And like Peregrini again, Tortorella also became the 'on-screen adjudicator,' as writer but also arbiter, to assure the audience that the answers were correct and that the game as a whole was properly run:

Yes, in all the programmes I made, or nearly all, writing the questions was just one part of it, for I often acted as the referee. I was referee on Doppio slalom, [...] and on La ruota della fortuna, and on M'ama non m'ama, too; but on the other hand, it was largely inevitable: who better to be referee than the autore? ${ }^{24}$

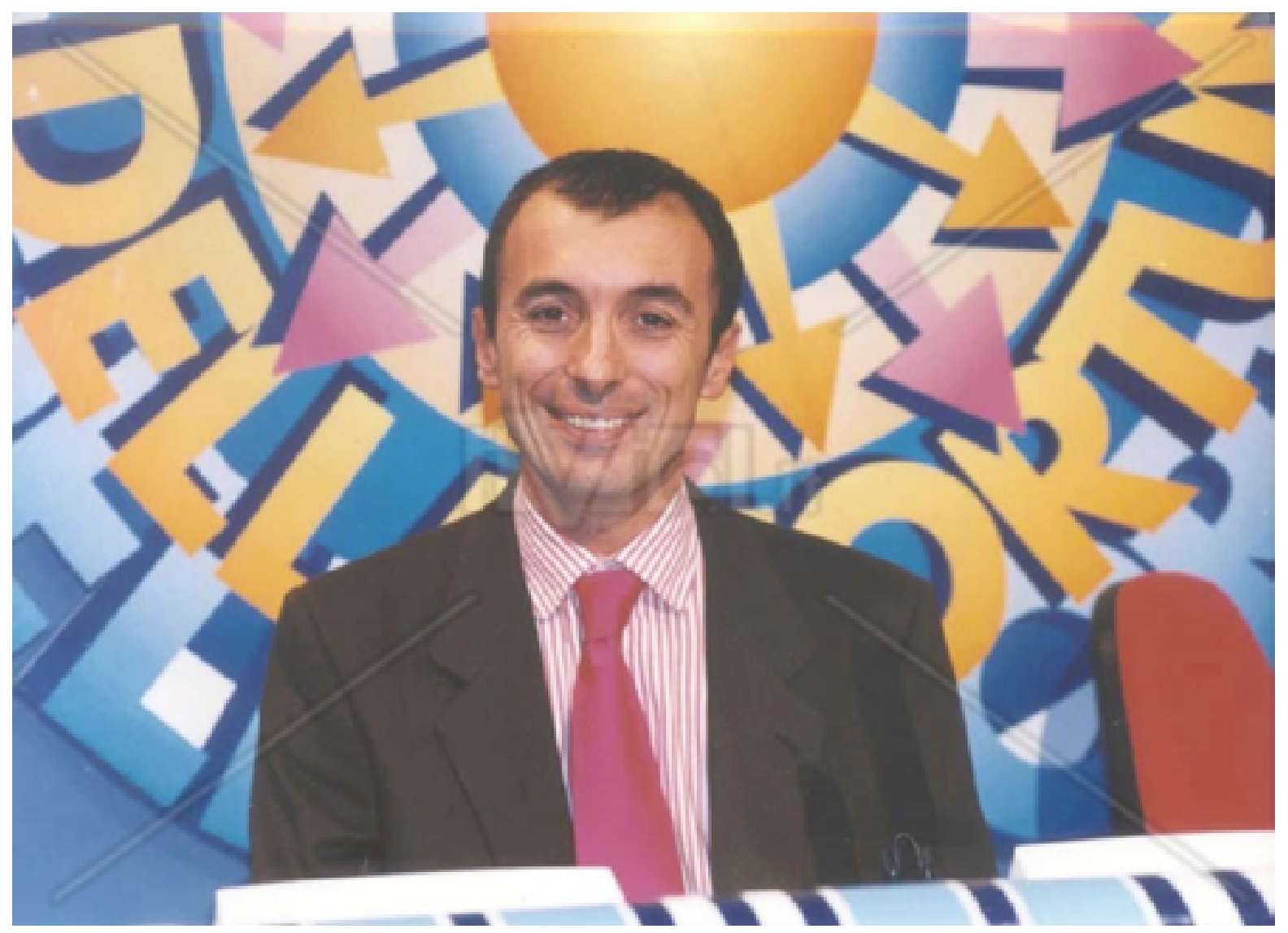

Davide Tortorella as "The referee" in La ruota della fortuna.

23 Interview with Ludovico Peregrini.

24 Interview with Davide Tortorella. 
In Italian TV's early years, as when commercial television first arrived, the game show writer was therefore a specialist, with a predominantly humanistic background, rather well educated, capable of taking on all aspects of the creative and production process (from writing the questions to casting the contestants and acting as on-screen 'adjudicator'). Thus, they became the presenters' trusted right-hand men. These multi-talented autori had significant scope even with programmes 'inspired' by American templates (Rischiatutto is based on Jeopardy) or directly adapted from formats (La ruota della fortuna from Wheel of fortune).

A more substantial change, though, would arrive as the formats market developed and the age of plenty arrived in the 2000s. The writers employed on the big productions doubled or even tripled in number. Indeed, in the most recent edition of the Italian adaptation of The money drop (2013), among 'internal'/senior writers (working in the production offices and in the studio) and 'external'/junior writers (setting questions from home), as many as eleven or twelve people were credited. But, above all, there has been a major and fundamental separation of roles. The game show autori are no longer asked to do everything; the trend is towards a more marked specialization and compartmentalization of roles, especially in the division of the two main tasks between specialist autori dedicated exclusively to questions, and autori working solely on casting.

Behind this diversification in the authorial roles and the distinct demarcation of responsibilities, there are several reasons. First, the writers must now also take on a series of formal tasks that were previously considered more ancillary. Indeed, the burgeoning development of the formats market and the resulting multitude of products has led to an increasingly meticulous and precise definition of all the graphical and visual details scrupulously included in the format package. The autori, then, must no longer confine themselves to the 'primary' aspects of a game show (the questions and the contestants) but must also continually monitor an array of other now-essential factors (lighting, jingles, graphical fonts, etc.) that used not to be deemed their responsibility.

But underlying this significant change are two factors: the greater importance afforded to the contestants in contemporary quizzes and a greater difficulty in recruiting them. All the autori interviewed agreed on this, albeit with subtle distinctions as to its causes.

The casting researcher's job arises from the increasingly important role of the contestant and, therefore, from the need to hold many more castings, because that's obviously what you have to do to find more worthwhile contestants, even though the result is always unsatisfactory. ${ }^{25}$

To fulfil this more demanding commitment, some autori must be continually out and about holding castings throughout the country. Consequently, they no longer have time for the other tasks and, even less so, for writing the large volume of questions that the game needs, especially if it is stripped with a daily slot (with five to seven broadcasts a week), as became common in Italy from the 1990s.

This production model, and the resulting drive towards greater specialization in the creative roles, began to be adopted in Italy with the first editions of Chi vuol essere milionario? and became standard current practice with successor quizzes like The money drop. The 'single autore,' the deus ex machina of game shows developed through a process more handcrafted than industrial, now belongs to the past.

\section{Question Setting Style}

The sole writer (like Ludovico Peregrini for Rischiatutto) or small team of autori was replaced in the 2000s by more complex and elaborate arrangements featuring a tighter demarcation of roles. This new form of organization also demanded a more structured 'hierarchy' among the professionals writing the programme. In particular, the need arose

25 Interview with Davide Tortorella. 
for a head writer, or capo autore, who worked closely with the programme's producers, presenter and director and who, above all, coordinated the writers and gave the broadcast a specific style.

This distinctive style derived from a particular creative effort centred on writing the questions, in line with rather strict constraints. Indeed, the head writer followed a series of parameters determined both by the original format and by the specific requirements of adapting it for domestic consumption. The contemporary format, in fact, not only sets out in minute detail all the visual aspects and the staging but also, of course, ties the questions to a particular form, such as multiple choice in Chi vuol esser milionario? or The money drop. The form of the questions is predetermined by the programme; the content, however, is a matter of authorial choice, especially that of the head writer.

When adapting a globally successful format, like Chi vuol essere milionario?, it is therefore vital to establish a question style that reflects the country's taste and culture. The writers agree that, having seen different international editions of a format, very little of their overseas colleagues' work is usable in the Italian version, especially as regards the question content.

Take France, for example; as my wife is French, I watched a lot of Qui veut gagner des millions? in French. At first sight, I thought there were some great ideas for questions, but I wouldn't actually have used a single one in Italy - not because they weren't good questions but because they had nothing to do with us, with our taste, our culture; that's the point. I have also seen the English version and others, too. I think this actually applies to autori of Chi vuol essere milionario? all over the world: I'm sure no one has "pinched" any questions, because tastes differ widely. ${ }^{26}$

So is there a national style for game show questions? And what role does the head writer play in shaping it? The answer to the first question is a firm 'yes,' at least for Italy. As we have seen, the Italian game show has a long tradition both of taking 'inspiration' from international models and of 'localizing' them in a strongly Italianized way: an accentuated light-entertainment aspect, hybridizing with elements from variety, a presenter given to histrionics, and contestants with strong characters are all features of the country's game show tradition. These have persisted despite the game show production model's transition from the handcrafted approach in TV's early days to the more rigid mechanisms dictated by the formats.

As head writer for the early episodes of Chi vuol essere milionario?, Peregrini, for example, set the writers a series of rules for writing the questions. His then colleague Ilenia Ferrari recalls:

The type of questions set in the game depended heavily on Ludovico Peregrini's ideas. He had laid down several specific question categories, which he asked us to write to. For instance, some of the questions had to be purely visual. A classic example is 'How many orders of arcade does the Colosseum have?', with multiplechoice answers 'One, two, three or four'. The significance of the visual questions was that they sought to engage both the contestant in the studio and, above all, the viewers at home, who thus felt involved. Peregrini would say: 'I want people to reflect, to think and to picture whether there are two or three. ${ }^{27}$

Besides the head writer, each individual writer adopted a particular style in constructing the questions. One writer came to Chi vuol esser milionario? with long experience on a popular science programme (La maccbina del tempo). She contributed an enjoyable strand of questions with a naturalistic theme and a touch of irony that made great play of innocent double meanings. In infusing the genre with comedy and variety elements, these light-hearted aspects are entirely consistent with the history of Italian game shows. This is precisely because they enable the presenter (once Mike Bongiorno, now Gerry Scotti) to ham it up with the contestants, to playfully tease them, and to have some repartee with the audience. 
This light-hearted flavour is an explicit part of the thinking behind Chi vuol esser milionario?, whose authorial team has decided to kick the game off in overtly comic vein.

One autore in the group was Martino Clericetti, whose experience was entirely in TV comedy and who had introduced this idea: 'The first question is there to relax the contestant, so let's make it entertaining and jokey; anyway, we know it's only worth 500,000 lire, and it's easy.' And so we decided that the first couple of questions always had to include a joke. We ensured that the first few questions always had something fun or silly about them. It worked, especially because it enabled Gerry Scotti [the presenter] to have some friendly banter with the contestant and with the viewers at home..$^{28}$

\section{The Casting Profession: Seeking the 'Character'}

Once a relatively simple task, casting in contemporary game shows is now seen as more complex, requiring professionals dedicated specifically to this aspect of the programme. If the question writing style is the first significant matter to attend to for game show writers adapting international formats, finding suitable contestants is the second most vital ingredient for a successful programme.

An awareness of the crucial importance of casting began to emerge in Italy during production of Chi vuol essere milionario?, a programme that requires increasingly detailed, complex general cultural knowledge, the further the player progresses through the game. The autori realized that, compared to the show's early editions, it was becoming increasingly hard to find appropriate contestants. Peregrini summed up the perception of this development most succinctly and, with it, the need to treat casting as a specific, separate activity:

We held castings every year, and we were desperate, because back in 2002, out of 100 candidates at a casting, we would take 50 , whereas in 2010 , we were down to $5 .{ }^{29}$

According to the game show writers, this problem has many causes. The first is, very simply, the lower general standard of knowledge found among aspiring game show contestants. Most of the writers interviewed concur in pointing the finger at the general decline in the average level of culture among the population, caused in turn by an erosion in school standards. Peregrini, again, is convinced of this:

It's true, people didn't know anything any more: I see an impoverishment in Italian culture, partly due to the schools, and a very considerable one, at that. ${ }^{30}$

A second thesis as to the particular casting difficulties concerns eminently televisual factors, namely a decisive shift in the target audience for game shows, as the multichannel market dawned. According to this theory, owing to the ample TV-channel supply, the more cultivated sections of the population are increasingly abandoning the generalist networks (the game show vehicles par excellence) for more specialized channels.

I believe now that the slightly more educated audience, which had always watched Canale 5 , is turning its attention to the satellite offering and the many and varied digital networks[...]. It has a different make-up to the audiences on the generalist networks, who tend to be less cultivated. Educated people still exist; they are just watching other things. ${ }^{31}$

\footnotetext{
28 Interview with Ilenia Ferrari.

${ }^{29}$ Interview with Ludovico Peregrini.

30 Interview with Ludovico Peregrini.

31 Interview with Ilenia Ferrari.
} 
To these initial explanations, we should add that, in the post-reality era, being on television holds much less cachet than it used to, and many people who would have felt intimidated are now rather more comfortable about coming forward, which they do quite happily. This effect is even more marked with game shows, compared to other kinds of programme, because they offer the added hope of winning some money in tough economic times.

The especially interesting point, though, is the widespread perception among game show professionals of a particular difficulty in finding suitable contestants for the programmes: while there is certainly a growing mass of people wanting to appear, they seem to be less educated, in general, than in the past. So casting becomes like looking for a needle in a haystack.

To address this situation, as we have mentioned, autori were enlisted to work exclusively on game show casting. Interestingly, these professionals do not necessarily have specific experience in game shows, but rather they specialize in recruiting people to appear on television full stop. Thus, knowledge of selection techniques takes precedence over familiarity with how game shows work. Hence, it is vital to maintain continual dialogue with the colleagues preparing the questions, for it is they who determine the type and level of expertise that the programme needs. This information must therefore be conveyed very accurately to those running the casting, to avoid the risk of the questions not being suitable for the people selected to answer them. So if, on one hand, this division of tasks may appear practical and efficient, on the other, it entails a very high risk of latent conflict between the two efforts and of things coming unstuck.

As for the production routines, the prevailing model (introduced for Chi vuol essere milionario? and retained for The money drop) envisages two teams, of two autori each, dedicated entirely to casting. In turn, one team is always out and about, both in the major centres (Milan, Rome, Naples, Bari, Palermo, etc.) and in the provinces, combing Italy for talent as finely as possible.

In truth, we have been to every region, and not just the main cities. One thing we wanted was to go to the little places, too, because otherwise we would have lost a part of Italy that perhaps would not have gone to Rome, Milan or Palermo for the castings. And so we also held them in towns like Pescara, Pesaro, Perugia and other smaller centres. ${ }^{32}$

While one team is out recruiting, the other stays in the TV studio to brief the selected contestants just before the show, advising them how to do their best and how to avoid making a bad impression.

We chatted to the contestants in the morning, as well, explaining what kind of game it was and passing on tips and tricks for how to be good contestants [...]. We tried to gee them up a little, saying things like: 'Hey, we're not going to pick your pockets; on the contrary, you can win yourself some money, so have fun, show everyone what lovely people you are and do your very best. ${ }^{33}$

But the casting autori must not select the contestants for their knowledge and reasoning ability only. Traditionally, Italian game show contestants must also, if not primarily, be 'characters.' Being a character means having personality, a particular life story, something curious about them that the presenter can use during the programme. From the start, Mike Bongiorno did not want to confine himself to asking the questions and building up the suspense; he wanted 'human beings' with something special to tell, because the game unfolds like the journey of a hero that the viewers tend to identify with:

Mike was very interested in the characters, because the characters were what made the show what it was, in effect. Of course, if the character was also erudite, so much the better, but the important thing was how they came across, their face, their character, their story - which is what we wanted to tell and which Mike told very well, moreover - rather than what they knew. ${ }^{34}$

\footnotetext{
32 Interview with Angelo Mandelli, autore (casting) of TV game shows.

33 Interview with Angelo Mandelli.

34 Interview with Ludovico Peregrini.
} 
Gerry Scotti, too, Mike Bongiorno's heir in many respects as presenter of Italy's most popular quiz programmes, along with many other presenters, has the same interest, thus helping to put the 'show' into the game show.

So not even the quiz show escapes from the variety influence, which has always been Italian television's defining feature, suffusing more or less directly all the other genres. It is no surprise, then, that the most successful game show of recent years, Avanti un altro!, (2011 to the present) makes great play of this aspect, presenting a cavalcade of bizarre, unconventional characters for presenter Paolo Bonolis to interact with to brilliant effect. The casting autori are therefore asked to find contestants who, on one hand, are knowledgeable enough not to fall at the first hurdle but on the other, strong enough characters to give the presenter some entertaining grist to work with. Once again, the game show autori have limited but vital scope for ensuring the programme's success. It is a profession called to work increasingly on the nuances (e.g. the style of the questions, and finding suitable contestants) that add colour to the production.

\section{Bi ography}

*This essay was conceived and produced jointly by the two authors. As for the actual writing, Massimo Scaglioni is responsible for sections 1 and 3; Axel Fiacco, for sections 2 and 4.

Axel Fiacco is a writer and format creator for Endemol Italia. He has worked as Content Manager for MTV Italia and Content Development Manager for Mediaset. He is the author of several books on television, most recently Fare televisione. I format (Laterza, 2013).

Massimo Scaglioni, PhD, is Assistant Professor of Media History at the Catholic University of Milan. He also teaches Television Communication and Transmedia Narratives at Università della Svizzera Italiana (USI), Lugano. In addition, he is the author of several books on media and broadcasting history in Italy. He is Research Coordinator at the Research Centre for Television and Audiovisual Media at the Catholic University, Director of Studies of the Masters course "Fare TV. Analisi, Gestione, Comunicazione" at ALMED (the University's postgraduate media school) and a member of the editorial boards of the scientific journals "Bianco e Nero" and "Comunicazioni Sociall". In 2012, he was short-term Visiting Professor at Carleton University, Ottawa (Canada). 